\title{
SHEAR STRENGTH OF BRICK MORTAR INTERFACE FOR MASONRY IN LIMA CITY
}

\author{
Luis Lavado ${ }^{1,2^{*}}$, Jorge Gallardo ${ }^{1,2}$ \\ ${ }^{1}$ Civil Engineering Faculty, National University of Engineering, Lima, Peru. \\ 2 Japan-Peru Center for Earthquake Engineering Research and Disaster Mitigation, Lima, Peru.
}

Received: 29/06/2019 Accepted: 07/08/2019

\begin{abstract}
Masonry structures constitute a large proportion of the building inventory in Lima and in most cities in Peru, mainly because of their benefits in terms of low cost, good mechanical properties and easily worked. It was observed in the cyclic loading test of clay masonry walls carried out at the Structural Laboratory of the Japan-Peru Center for Earthquake Engineering Research and Disaster Mitigation (CISMID) that the modes of failures can be mainly generated by shear forces. Based on the previous information, it is known that diagonal cracking and slip of the mortar-brick joints are the dominant failure mechanisms of confined masonry walls.

In order to determine the mechanical behavior in the mortar-brick joint, an experimental program was carried out, by using industrial and handmade clay bricks. The test specimens were specifically designed to transmit pure shear along the bed joints under certain constant levels of compressive stress normal to the bed joint. The results of experimental shear tests are presented and discussed. It is then found a consistency between the behavior of masonry joints under shear with the Mohr Coulomb criterion. The shear failure capacity was influenced by the brick type, pre-compression load level and mortar type. It is also noticed in this experimental study that the pre-compressive stress normal to the bed joints significantly increase the shear strength of the mortar-brick joint.
\end{abstract}

Keywords: Masonry, direct shear, handmade brick, interface.

\section{INTRODUCTION}

Masonry buildings can be found in many cities in Peru, mainly due to their special advantages, including low cost, good mechanical properties and easily worked. The common materials for this construction system are the mortar and the brick, they have certain varieties such as the type of brick, the indentation of the brick wall and the quality of the joints of mortar.

With the development of computational techniques, it is possible to represent numerical modeling of confined masonries, however, it is required to know the basic properties of their elements such as the units, mortar, and unit-mortar interface. This information is not easily available due to the lack of research on the area. In this regard, further studies are necessary in order to enrich the database of the properties of the elements that constitute the walls of confined masonries.

Different researches in masonry walls have been developed in the Structural Laboratory of the JapanPeru Center for Earthquake Engineering Research and Disaster Mitigation (CISMID). These studies include the cyclic loading test of masonry walls made with clay brick units that are used mainly in the expansion areas of the urban zones in Lima, with the aim of knowing the behavior of the confined masonry wall (Figure 1).

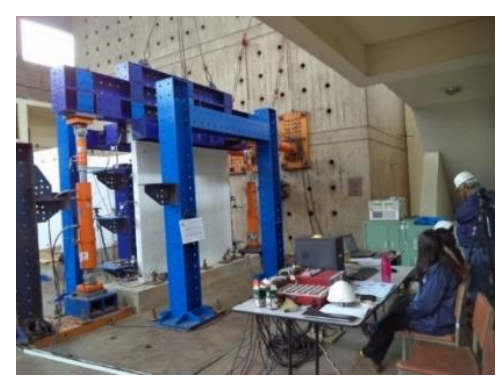

Figure 1. Cyclic loading test of masonry walls in the Structural Laboratory of CISMID

It was observed in the cyclic loading test of masonry walls that the modes of failures can be mainly generated by shear forces. It has also been seen diagonal cracking and slip of the mortar-brick joints are the dominant failure mechanisms of confined masonry walls (Figure 2).

The weakest link in masonry assemblages is often the bond between the unit and mortar. Lourenço (1996) indicates that the unit-mortar interface has two

* Corresponding author:

Imlavadol@uni.edu.pe 
different behaviors in the bond, the first one is associated with tensile failure and the other is related to the shear failure.

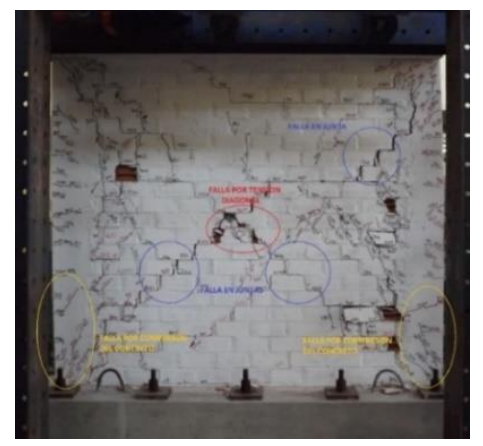

Figure 2. Failure Mechanisms in confined masonry walls

To analyze the shear failure of the brick-mortar interface, various types of experimental approaches (Figure.3) were carried out in the last decades in order to determine the shear strength. These may include the triplet test (Figure.3-a) that was used by Lourenço et al (2004). Meli (1973) used another test configuration (Figure.3-b) to study the shear response. Abdou et al. (2006) made a controlled system (Figure3-c) where they tested hollow and solid bricks and found that the shear strength of masonry with hollow bricks is higher compared to solid bricks.

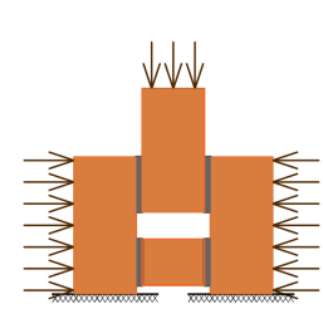

(a)

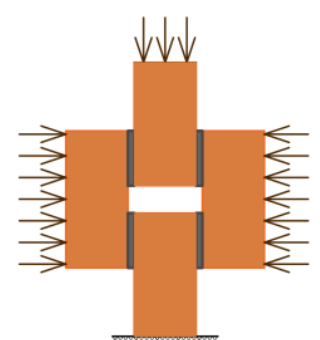

(b)

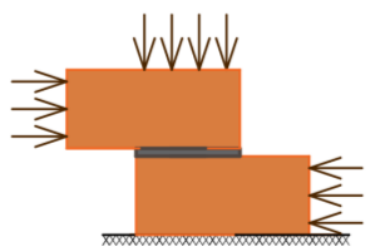

(c)

Figure. 3. Different types of shear tests: (a) Triplet Test, (b) Meli Test, (c) Direct Shear

Within the literature regarding the interface mortarbrick behavior, the Coulomb friction law is used to represent this shear failure with moderate precompression levels. In this paper, the Mohr-Coulomb criterion is applied, where the relation is given in Eq. (1).

$$
\tau=\tau_{0}+\mu \sigma
$$

Where:

$$
\tau \text { : Shear strength }
$$

DOI: https://doi.org/10.21754/tecnia.v29i2.707

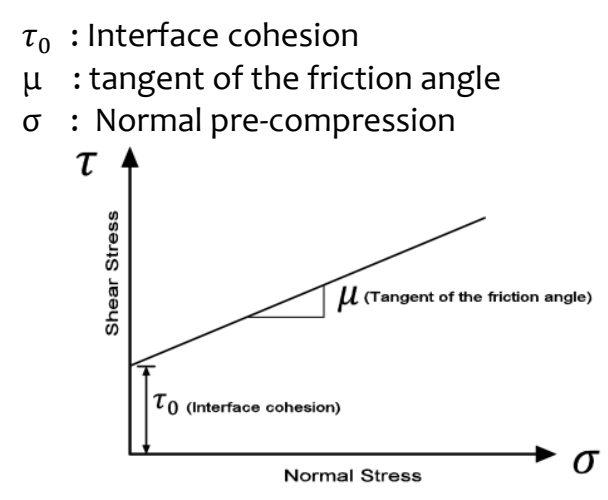

Figure. 4. Mohr-Coulomb criterion

\section{MASONRY JOINT SHEAR TEST}

The shear test enables to find the shear strength of the masonry joint subjected to shear loads. For the test, it has been built a triplet shear specimen which consists of two full bricks and two halves of bricks separated each other a certain distance as shown in Fig 5 .

The test consists of loading a pre-compression vertical load of confinement. While the vertical pressure remains constant, a horizontal load is applied in the two halves of bricks, providing the shear strength of the joints. The tests were made with different precompression vertical stresses. Specimens were tested to failure.

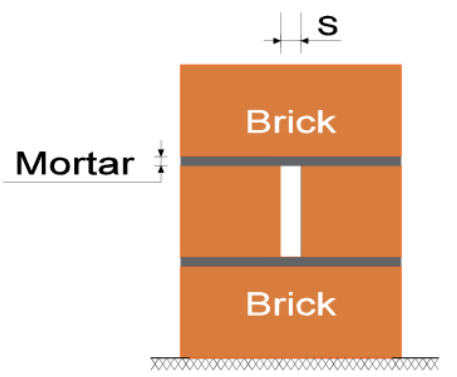

Figure 5. Masonry specimens

When the maximum shear capacity of the specimens is reached at a particular level of normal stress, it is registered as the shear strength. This shear strength is calculated in terms of the area resisting to shear by the Eq. (2).

$$
V=\frac{P}{2(A-S d)}
$$

Where:
$\mathrm{V}$ : Shear strength
$P$ : Maximum shear load
A : Area of brick unit
d : Depth of the brick unit
$S$ : Separation between the two halves of bricks 


\subsection{Failure Types}

The evaluation of the shear strength of the masonry joint is still a complicated task since different failure mechanisms can be observed. Failures occur when the application of forces exceed the maximum shear strength of the total assemblage, this may be generated in the unit bricks, mortar or brick-mortar interface.

\subsubsection{Brick failure}

Depending on the quality of the brick units, the stresses produced by the lateral and vertical forces may exceed the stress resistance of the brick, it is then produced the failure by the brick units instead of the mortar or the joint-mortar.

\subsubsection{Mortar failure}

A good adherence between the brick and the mortar as well as a high resistance of brick units may bring about a mortar failure. This failure is represented by the crushing of mortar when the strength of brick units has a high value compared to the brick units.

\subsubsection{Joint failure}

This type of failure depends on the bond of the joint between brick and mortar. Most cracks in masonry occurs due to the joint failure. When the units of masonry have high resistance compared to the mortarbrick interface, a displacement may occur in the joint.

Shear stresses generated in the joint must to exceed the shear capacity of the interface so that a displacement may happen.

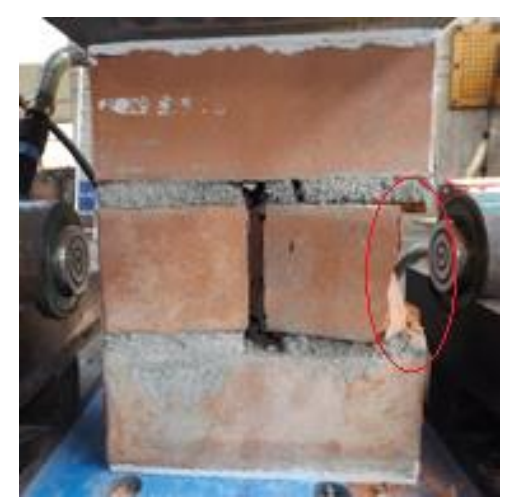

Figure 6. Brick units failure

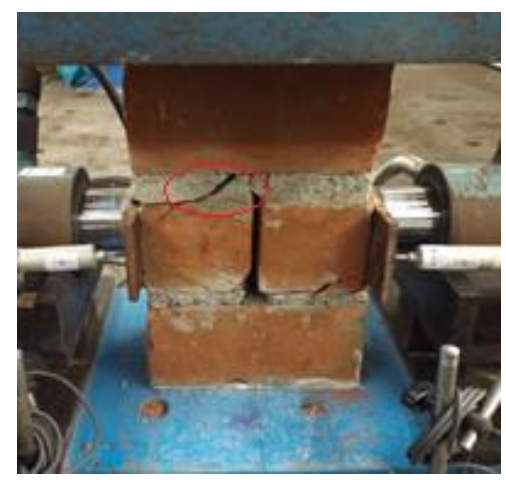

DOI: https://doi.org/10.21754/tecnia.v29i2.707
Figure 7. Mortar failure

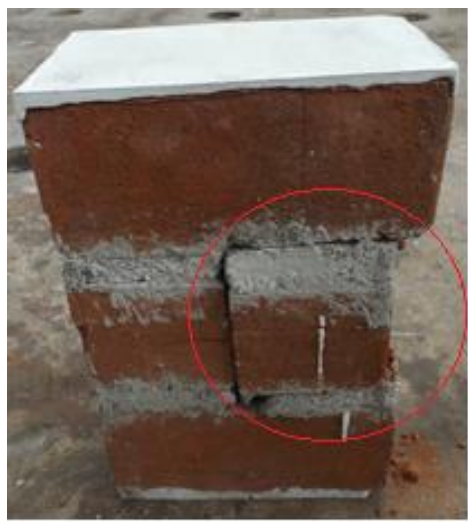

Figure 8. Joint Failure

\section{EXPERIMENTAL PROGRAM}

\subsection{Instrumentation and Test Setup}

Shear tests were performed in the Structural Laboratory of CISMID. Three hydraulic actuators with a maximum capacity of $200 \mathrm{kN}$ were used in the test, two were positioned in horizontal direction and the other one in vertical direction. Linear Variable Displacement Transducers (LVDT) were utilized as displacement control. By means of a data acquisition system, it was possible to connect the sensors with a computer. The communication with the sensors was achieved by the use of RS232 or with an Ethernet LAN connection.

\subsection{Specimen Preparation}

Surveys were carried out to determine which are the most productive factories of bricks in Lima and to study the characteristics of the bricks produced by each one of them. It was then possible to decide the bricks to be used in this experimental program.

Depending on the manufacturing method, the clay bricks can be handmade bricks and industrial bricks. Most of the large companies of bricks have sophisticated process technologies such as the firing process or drying process, which allows them to obtain better quality products. On the contrary, the majority of small brick factories present a high degree of informality due to the fact that they use artisanal techniques to manufacture their products.

In the province of Lima, the brick companies are mainly located in the District of Lurigancho, in the Centro Poblado Menor Santa María of Huachipa, in the Eastern area of Lima. They also are founded in the district of Puente Piedra and Carabayllo in the Northern area of Lima. 
Brick units from six factories were used, three of them were industrial bricks and the other three were handmade bricks. In the map of Lima shown in Figure 9, the arrows indicate the areas from where the handmade units were obtained.

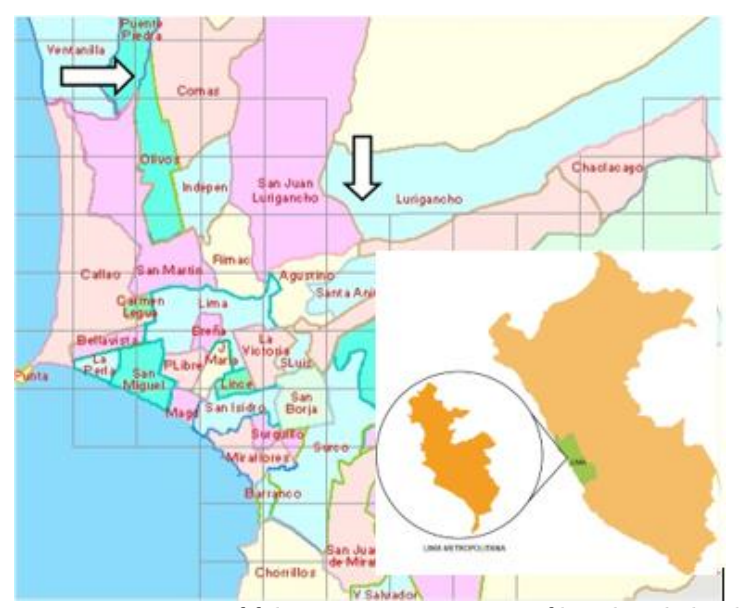

Figure 9. Points of fabrication in Lima city, of handmade brick units used in this study.

Two categories of bricks are considered in this study, the first one, identified as IND-01, IND-02, and IND-03, represents industrial bricks. The other type is the handmade bricks which are identified as ART-01, ART02, and ART-03. Moreover, industrial bricks present a void area due to the vertical holes, whereas handmade bricks contain frogs which are depressions in the face of the brick as it is observed in Fig11.

Shear tests were carried out to determine the mechanical properties of the masonry joints. It was elaborated 48 specimens and it was used two types of mortars in order to search their effects in the masonry joints.

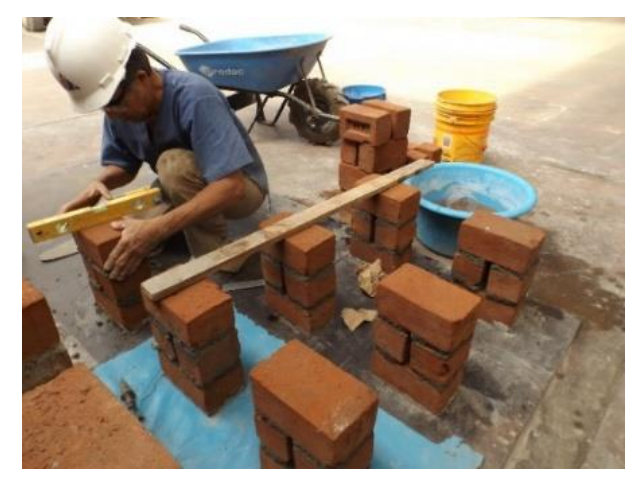

Figure 10. Specimens preparation.

For the mortar in all cases, it was used the cement Portland Type I and fine aggregate. Two types of mortar with cement-sand volumetric ratio 1:3 and 1:5 were used, both without lime, which are considered for structural walls according to the Standard E.070 masonry design.
For each type of brick 4 specimens were made with cement-sand volumetric ratio 1:3 and 4 specimens were made with cement-sand volumetric ratio 1:5

Masonry buildings located in the expansion areas of the urban zones in Lima usually do not use the lime for the elaboration of the mortar. Hence, in this study, it has not been incorporated for the elaboration of the mortar.

\begin{tabular}{cc} 
Table 1. Identification of each type of brick. \\
\hline Brick Type & Identification \\
\hline Industrial Type 1 & IND-1 \\
Industrial Type 2 & IND-2 \\
Industrial Type 3 & IND-3 \\
Handmade Type 1 & ART-1 \\
Handmade Type 2 & ART-2 \\
Handmade Type 3 & ART-3 \\
\hline
\end{tabular}

Table 2. Brick specimens: Suction and Absorption

\begin{tabular}{ccc}
\hline $\begin{array}{c}\text { BRICK } \\
\text { TYPE }\end{array}$ & $\begin{array}{c}\text { SUCTION } \\
(\mathrm{g} / 200 \mathrm{~cm} 2)\end{array}$ & $\begin{array}{c}\text { ABSORPTION } \\
(\%)\end{array}$ \\
\hline IND-01 & 40.56 & 13.41 \\
IND-02 & 46.75 & 13.2 \\
IND-03 & 42.69 & 12.1 \\
ART-01 & 80.7 & 15.48 \\
ART-02 & 36.76 & 13.71 \\
ART-03 & 99.39 & 15.27 \\
\hline
\end{tabular}

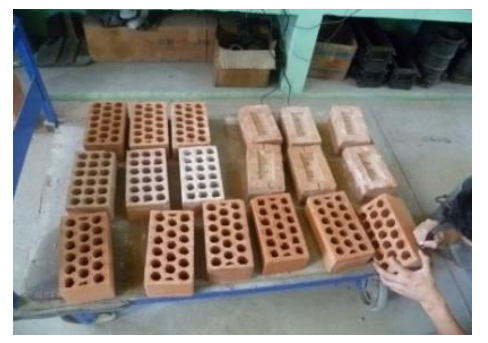

Figure 11. Presence of holes in industrial bricks compared to frogs in handmade bricks

\subsection{Testing and Measurements}

Before the shear test, it was applied at the top and bottom of the specimen, which are the contact areas of the specimen with the hydraulic actuators, a flat substance made of cement and gypsum to correct the superficial irregularity of the masonry and for avoiding eccentricity loads in the test.

After the process mentioned above, the masonry specimens were carefully fixed in the structure where the test was carried out.

In the vertical direction, the confinement load is applied by the hydraulic jack. The levels of load and their respective nominal stresses are shown below in the Table 3:

Table 3. Level of confinement of load in the vertical direction

\begin{tabular}{clllllllll}
\hline $\begin{array}{c}\text { Level of } \\
\text { confinement }\end{array}$ & 1 & 2 & 3 & 4 & 5 & 6 & 7 & 8 \\
\hline
\end{tabular}

Journal TECNIA Vol.29 N² July-December 2019 
Normal Stress

(MPa)

$\begin{array}{llllllll}0.1 & 0.2 & 0.3 & 0.4 & 0.5 & 0.6 & 0.7 & 0.8\end{array}$

In the horizontal direction, the load is applied to each brick portion (placed at the center of the specimen) increasingly up to the instant when the failure between the mortar and brick occurs.

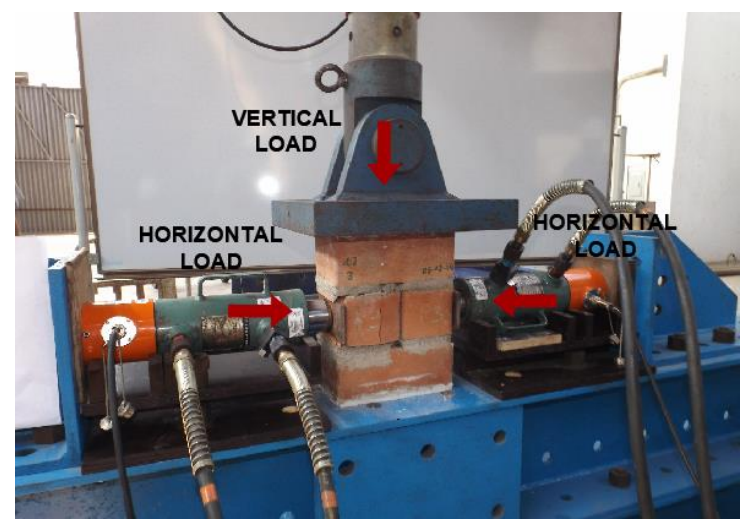

Figure 12. Configuration of the shear test.

\section{TEST RESULTS}

\subsection{Industrial Brick specimens}

In the case of specimens made with industrial bricks, it was observed a linear trend between the shear strength and the level of confinement expressed in normal stresses. Taking into account that each level of confinement increased 0.1 MPa applied at the top of the face of the brick, and by means of the Mohr-Coulumb criterion, the following expression can be proposed:

$$
\tau=0.288+0.262 \sigma
$$

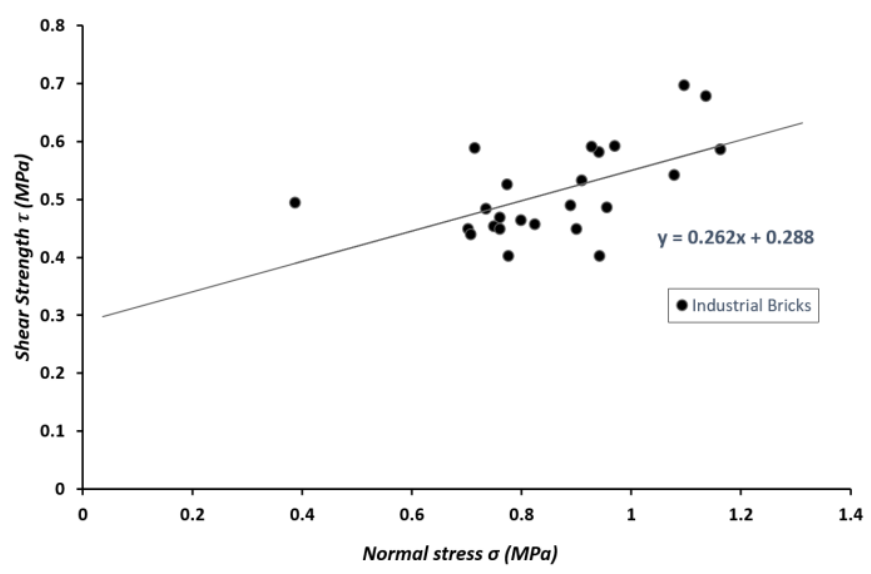

Figure 13. Relation between shear strength and normal stress in industrial bricks.

\subsection{Handmade Brick specimens}

In the case of handmade bricks, in the same way as industrial bricks, a growing linear trend is seen between the shear strength and the level of confinement expressed in normal stresses, for which the following expression is proposed:

$$
\tau=0.2364+0.2519 \sigma
$$

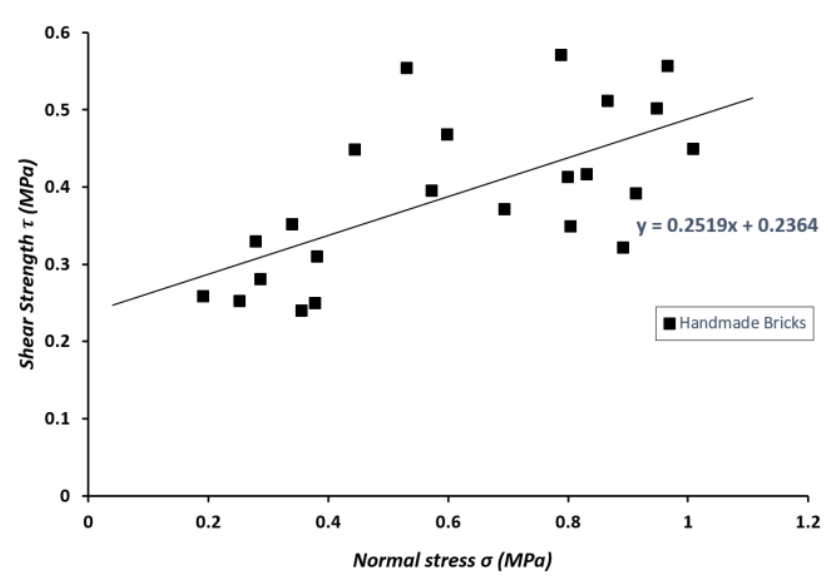

Figure 14. Relation between shear strength and normal stress in handmade bricks.

\subsection{Comparison between brick specimens}

Based on direct shear tests at different levels of precompression loading, the bonding relationship between the mortar and brick was characterized by a linear regression to obtain the expressions of the Mohr Coulomb failure criterion for the bricks used in the city of Lima, in both industrial bricks and handmade bricks. These results maybe used as reference values for the study of the behavior of masonry walls.

It can be seen in Figure 15 the global results of the study; industrial bricks are represented with circular shape whereas handmade bricks are shown with rectangular shape. From all these points, a line of increasing linear trend is obtained with the following expression:

$$
\tau=0.2224+0.3125 \sigma
$$




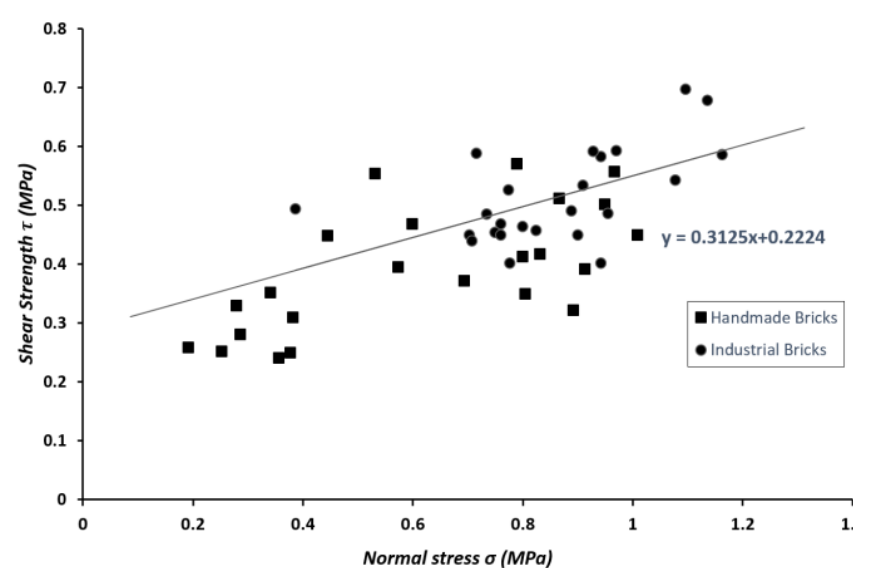

Figure 15. Relation between shear strength and normal stress in all the specimens

\section{CONCLUSIONS}

The mortar with cement-sand volumetric ratio of 1:3 presented a better behavior against the applied shear stress than the mortar with cement-sand ratio of 1:5. It was supposed initially that the cement provided resistance to the mortar. Due to the fact that the mortar with a ratio of 1:3 had more concentration of the cement than the mortar with a ratio of 1:5, the results have been as it was expected.

For industrial bricks, it was obtained in the brickmortar joint an average value of shear strength 0.51 MPa, while handmade bricks had in the brick-mortar joint an average value of shear strength of 0.39MPa.

In this study, it was found that shear strength of industrial bricks is a little higher than that of handmade bricks. This may be explained by the holes that the industrial bricks have. More research is recommended in order to identify a relation between the percentage of holes in brick units and the shear strength of the masonry.

It can be deduced that the adhesion between the mortar and the masonry unit has a great contribution to the resistance to the shear in masonry walls.

\section{ACKNOWLEDGEMENTS}

The authors are grateful to the Ministry of Economy of Peru, for the support of PP068 Project. We also extend our gratitude to Dr. Carlos Zavala Director of CISMID.

\section{REFERENCES}

[1] Zavala C, Estrada M, Aguilar Z, Lázares F 2010 Estudio De Microzonificación Sísmica y Vulnerabilidad en la Ciudad De Lima, Ministry of Housing, Construction and Sanitation.

[2] Zavala C, Estrada M, Aguilar Z, Lázares F 2012 Estudio de Microzonificación Sísmica, Mapas de Peligros Múltiples y Análisis de Riesgo de los Distritos del Cercado De Lima, Ventanilla y de las Ciudades de Chincha y Contumazá, Ministry of Housing, Construction and Sanitation.

[3] Izquierdo T 1995 Correlación para determinar las propiedades físicas y mecánicas de unidades o especímenes de albañilería.

[4] Meli R 1971 Propiedades mecanicas de la mampostria, Universidad Nacional Autonoma de Mexico.

[5] Lourenço, P 1996 Computational strategies for masonry structures. Dissertation/Thesis, ProQuest Dissertations Publishing.

[6] Meli R 1973 Behavior of masonry walls under lateral loads, Proc., 5 th World Congress on Earthquake Engineering.

[7] Abdou L, Saada R A, Meftah F, Mebarki A 2006 Experimental investigations of the joint-mortar behavior.

[8] Lourenço P B, Barros J O and Oliveira, J T 2004 Shear testing of stack bonded masonry 